\title{
Sulfonated nanocellulose beads as potential immunosorbents
}

\author{
Igor Rocha $(\mathbb{D} \cdot$ Natalia Ferraz $\cdot$ Albert Mihranyan • Maria Strømme • \\ Jonas Lindh
}

Received: 8 September 2017/ Accepted: 10 January 2018/Published online: 15 January 2018

(C) The Author(s) 2018. This article is an open access publication

\begin{abstract}
Herein 2,3-dialdehyde cellulose beads prepared from Cladophora green algae nanocellulose were sulfonated and characterized by FTIR, conductometric titration, elemental analysis, SEM, $\zeta$-potential, nitrogen adsorption-desorption and laser diffraction, aiming for its application as a potential immunosorbent material. Porous beads were prepared at mild reaction conditions in water and were chemically modified by sulfonation and reduction. The obtained $15 \mu \mathrm{m}$ sized sulfonated beads were found to be highly charged and to have a high surface area of $\sim 100 \mathrm{~m}^{2} \mathrm{~g}^{-1}$ and pore sizes between 20 and $60 \mathrm{~nm}$, adequate for usage as immunosorbents. After reduction of remaining aldehyde groups, the beads could be classified as non-cytotoxic in indirect toxicity studies with human dermal fibroblasts as a first screening of their biocompatibility. The observed properties make the sulfonated cellulose beads interesting for further
\end{abstract}

I. Rocha $\cdot$ N. Ferraz $(\bowtie) \cdot$ A. Mihranyan ·

M. Strømme · J. Lindh ( $\square)$

Nanotechnology and Functional Materials, Department of Engineering Sciences, Uppsala University, Box 534,

75121 Uppsala, Sweden

e-mail: natalia.ferraz@angstrom.uu.se

J. Lindh

e-mail: jonas.lindh@angstrom.uu.se

I. Rocha

CAPES Foundation, Ministry of Education of Brazil,

Brasília, DF 70040-020, Brazil development as matrix material in immunosorbent devices.

Keywords Periodate oxidation - Dialdehyde cellulose - Surface group density - Sulfonated beads . Cytotoxicity

\section{Introduction}

Nanocellulose has emerged as an interesting version of the extensively utilized polymer cellulose. Nanocellulose is a versatile material obtained from different sources, such as wood, algae and bacteria and consists of cellulose chains structured in nanometer sized fibers or crystallites (Dufresne 2013).

Nanocellulose obtained from Cladophora green algae has unique properties such as high surface area of around $100 \mathrm{~m}^{2} \mathrm{~g}^{-1}$, high degree of crystallinity up to $95 \%$, entangled fibrous web structure and excellent mechanical and rheological properties (Mihranyan 2010). It is obtained from filamentous green algae that can be harvested at various coastal areas around the world (Mihranyan et al. 2007). The unique features described above have contributed to the increasing interest in using Cladophora nanocellulose in biomedical applications such as in hemodialysis membranes, (Ferraz et al. 2012, 2013; Ferraz and Mihranyan 2014) for electrochemically controlled DNA extraction, 
(Razaq et al. 2011) DNA-immobilized immunosorbent membranes, (Xu et al. 2016) for adsorption of metals from solution and for size-exclusion virus removal (Metreveli et al. 2014; Asper et al. 2015; Gustafsson et al. 2016).

Our group has recently described the synthesis of Cladophora nanocellulose dialdehyde (DAC) beads by one-pot procedure in water under mild reaction conditions (Lindh et al. 2014, 2016; Ruan et al. 2016). The spherical DAC beads are spontaneously formed under the specified reaction conditions and circumvent the need of cumbersome bead formation processes. Cellulose beads, which are spherical particles with a diameter in the micro to millimeter range, have been used in a wide range of applications, including industrial, biotechnological and biomedical settings (Gericke et al. 2013). These applications also include the use of cellulose beads as immunosorption materials (Weber et al. 2005, 2010; Ettenauer et al. 2011).

Here we investigate the synthesis of porous sulfonated dialdehyde cellulose beads and anticipate their potential applications as hemocompatible immunosorbents. We foresee that the high degree of oxidation of the nanocellulose beads can be exploited to immobilize antibodies for tailored removal of specific toxins and further development of personalized treatments. The abundance of aldehyde groups on the surface of the beads provides excellent auxiliaries for mild and efficient coupling chemistry of e.g. amines and can be applied to bind sensitive biological substrates. Moreover, the spherical shape of the beads is beneficial for flow applications where the spheres reduce the backpressure and permit relatively high flow rates at moderate pressure. In all sorption applications a large contact area between the sorption material and the adsorbate is beneficial, which is catered for using the high surface area of the Cladophora nanocellulose. Further, the porosity of the beads might be tailored to induce sorption of biomolecules of certain sizes and thereby provide physical selectivity.

An important property for a number of immunosorbent materials is hemocompatibility. Blood-material interactions lead to the activation of blood cells and cascades resulting in coagulation and inflammation (Gorbet and Sefton 2004). In order to avoid the formation of clots and decrease the inflammatory response during blood-related procedures, an anticoagulant agent such as soluble heparin is administered to the patient (Olson and Björk 1993; Salmivirta et al. 1996; Alban 2005). Heparin is a sulfonated glycosaminoglycan polysaccharide obtained from internal organs of mammals and it is widely used in medical procedures involving blood withdrawal (Olson and Björk 1993; Cosmi and Palareti 2012). However, in the long term it can cause many side effects such as thrombocytopenia, hyperkalemia and osteoporosis (Junqueira et al. 2013). Therefore a procedure using a membrane or sorption material possessing anticoagulant properties could be of interest, as it would reduce the amount of heparin given to patients.

In this sense, material-surface modification by introducing heparin-like structures has been suggested to obtain antithrombogenic materials (Tamada et al. 1998; Ran et al. 2012). The introduction of sulfonated moieties in polysaccharides has been proposed as an alternative to heparin (Maas et al. 2012) since it is believed that the activity of heparin is due to the presence of sulfate, sulfamide and carboxylic acid groups (Silver et al. 1992; Tamada et al. 1998, 2002).

In the present study, a sorption material based on 2,3-dialdehyde cellulose (DAC) beads prepared with nanocellulose from Cladophora green algae was chemically modified with sulfonate groups with the ultimate aim of introducing anticoagulant properties. The surface modified material was characterized in terms of degree of sulfonation, surface area, porosity, $\zeta$-potential and size of the particles. Additionally, indirect cytotoxicity studies were performed with human cell lines as a first evaluation of the biocompatibility of the beads.

Cytotoxicity testing is part of the biocompatibility studies of medical devices and is required for all types of devices according to the international standards compiled as ISO 10993 (ISO10993-5 2009).

This work is the first part of a study aiming to develop advanced nanocellulose-based sorption materials with anticoagulant properties which could be used as a platform for coupling specific antibodies.

\section{Materials and methods}

\section{Chemicals}

Nanocellulose from Cladophora green algae was provided by FMC Biopolymer, U.S.A. Sodium 
metaperiodate, sodium bisulfite solution, sodium borohydride, and other chemicals were of analytical or reagent grade and were used as received. Dulbecco's Modified Eagle Medium (DMEM-F12), Dulbecco's phosphate buffered saline (PBS) and RPMI1640 medium were purchased from Sigma-Aldrich (Germany) and used as received. Alamar blue cell viability reagent was purchased from Invitrogen (U.S.A.). Fetal bovine serum (FBS, Hyclone ${ }^{\mathrm{TM}}$ ) was purchased from GE Healthcare Life Sciences (U.K.).

Preparation of materials

\section{Preparation of DAC beads}

Cladophora nanocellulose, $12 \mathrm{~g}$, was dispersed in $1.8 \mathrm{~L} 10 \mathrm{mM}$ acetate buffer ( $\mathrm{pH} 4.5)$ containing dissolved $\mathrm{NaIO}_{4}, 79 \mathrm{~g}$, (about $5 \mathrm{~mol}$ per mol of anhydroglucose unit) and $180 \mathrm{~mL}$ 1-propanol as a radical scavenger. The reaction was carried out in the dark with magnetic stirring. Any excess of periodate was quenched by addition of $24 \mathrm{~mL}$ ethylene glycol and stirring for $30 \mathrm{~min}$. The mixture was then transferred to test tubes and centrifuged for $10 \mathrm{~min}$ at $2600 \mathrm{~g}$. After being centrifuged the cellulose particles were collected at the bottom of the tubes and the supernatant could easily be poured off. Then water was added to the tubes and the cellulose was resuspended, the mixture was then vortexed for $5 \mathrm{~min}$ and centrifuged for $10 \mathrm{~min}$ at $2600 \mathrm{~g}$. This was repeated four times with water, four times with ethanol and two more times with water to ensure that byproducts or unreacted substances were washed off from the porous beads; at the end of the washing procedure the $\mathrm{pH}$ was checked to make sure that it was neutral and the conductance was measured until reaching the conductance of deionized water. In order to dry the beads for characterization and cell studies, they were washed and centrifuged three more times with ethanol and left to air-dry for $24 \mathrm{~h}$ in the fume hood.

\section{Preparation of sulfonated beads}

The never-dried DAC beads were sulfonated using $14 \mathrm{~mL}$ of $\mathrm{Na}_{2} \mathrm{SO}_{3(\mathrm{aq})} 40 \%$ (w/v) for each $5 \mathrm{~g}$ of neverdried material (corresponding to $0.5 \mathrm{~g}$ dried DAC) for $24 \mathrm{~h}$ and named SDAC. The samples were purified using the same protocol as above. The drying procedure was performed as mentioned before.

\section{Characterization}

\section{Fourier transform infrared (FTIR) spectroscopy}

FTIR spectra during the course of the periodate oxidation reaction to produce the DAC beads were collected on a Bruker Tensor 27 (Germany) spectrometer with $\mathrm{KBr}$ pellets $\left(1 \%_{\mathrm{wt}}\right.$ sample). The resolution was $4 \mathrm{~cm}^{-1}$ and 100 scans were averaged. Two analyses were made with each sample. A rubber band background was subtracted from all spectra using the instrument Software (Opus 7.0, Bruker, Germany).

\section{Quantification of aldehyde and sulfonated groups content}

The DAC samples were transformed to aldoximes via Schiff base reactions with hydroxylamine according to a literature procedure (Kim et al. 2000) and were analyzed for elemental composition $(\mathrm{C}, \mathrm{H}, \mathrm{N}, \mathrm{O}$ and $\mathrm{S})$ by Analytische Laboratorien (Lindlar, Germany). Briefly, never-dried DAC (corresponding to a dry weight of $100 \mathrm{mg}$ ), $40 \mathrm{~mL}$ of acetate buffer ( $\mathrm{pH} 4.5$ ), and $1.65 \mathrm{~mL}$ of hydroxylamine solution (aqueous, $50 \%$ wt $)$ were added to a round bottom flask under magnetic stirring. The reaction mixture was stirred at room temperature for $24 \mathrm{~h}$. The product was thoroughly washed with water and dried under reduced pressure prior to elemental analysis. The SDAC and the reduced SDAC samples (described in Sect. 2.4) were purified following the same procedure described for the DAC beads and were dried under reduced pressure prior to elemental analysis $(\mathrm{C}, \mathrm{H}, \mathrm{N}, \mathrm{O}$ and $\mathrm{S})$.

\section{Determination of sulfonated group content}

The amount of sulfonated groups present in SDAC was determined by conductometric titration of the total charged groups in the sample. About $100 \mathrm{mg}$ of material was dispersed in $60 \mathrm{~mL} \mathrm{NaCl}(0.01 \mathrm{M})$ through high-energy ultrasonication (Vibracell $600 \mathrm{~W}, 20 \mathrm{kHz}$, U.S.A.), and the $\mathrm{pH}$ was adjusted to 2.8 by adding $\mathrm{HCl}(1 \mathrm{M})$ to ensure that all sulfonated groups on the nanocellulose surface were protonated. The dispersion was purged with nitrogen for $20 \mathrm{~min}$ prior to titrations in order to remove dissolved gases 
that could influence the $\mathrm{pH}$ of the medium. The titration was made with $\mathrm{NaOH}(0.05 \mathrm{M})$ using a Mettler Toledo T70 titrator (Lloyd et al. 1993; Beck et al. 2015).

\section{Scanning electron microscopy (SEM)}

SEM micrographs of the different nanocellulose materials were recorded with a LEO 1550 SEM instrument (Zeiss, Germany). Samples were mounted on aluminum stubs using a double-sided adhesive carbon tape and sputtered with $\mathrm{Au} / \mathrm{Pd}$ with a plasma current of $30 \mathrm{~mA}$ for $30 \mathrm{~s}$.

\section{$\zeta$-Potential measurements}

Dispersions of $0.001 \% \%_{(\mathrm{w} / \mathrm{w})}$ of the modified materials in $\mathrm{NaCl}_{\text {(aq.) }}(10 \mathrm{mM})$ were prepared through highenergy ultrasonication (Vibracell $600 \mathrm{~W}, 20 \mathrm{kHz}$, U.S.A.), and $\mathrm{pH}$ was adjusted to 6.5 with $0.05 \mathrm{M}$ $\mathrm{NaOH}$. The electrophoretic mobility of the samples was measured using a universal dip cell, a ZetaSizer Nano instrument and a ZetaSizer Properties Software, all from Malvern Instruments, U.K.

\section{Specific surface area (SSA) and pore size distribution analysis}

The nitrogen adsorption-desorption experiments were performed at $77 \mathrm{~K}$ using a Micrometrics ASAP 2020 gas sorption instrument (Micromeritics, Norcross, GA, U.S.A.). The samples were degassed at high vacuum $\left(1 \times 10^{-4} \mathrm{~Pa}\right)$ at $80^{\circ} \mathrm{C}$ for $24 \mathrm{~h}$ prior to analysis. The SSA was calculated using the Brunauer-Emmett-Teller (BET) method (Brunauer et al. 1938) on the adsorption branch of the isotherm at $\mathrm{P} / \mathrm{P}_{0}$ between 0.05 and 0.3 . The pore size distribution was calculated using the Barrett-Joyner-Halenda (BJH) method (Brunauer et al. 1938; Landers et al. 2013) based on the desorption branch of the isotherm.

\section{Particles size distribution analysis}

Samples were dispersed in water and sonicated and then analyzed with laser diffraction using a Mastersizer 3000 instrument (Malvern Instruments, UK).
Cell studies

Preparation of reduced sulfonated beads

The remaining aldehyde groups in the SDAC beads were reduced to hydroxyl groups with $10 \mathrm{mg}$ of $\mathrm{NaBH}_{4}$ per $5 \mathrm{~g}$ of wet material (corresponding to $0.35 \mathrm{~g}$ dried SDAC) and purified using the same protocol described for the other samples. The sample was named RSDAC.

\section{Cell culture}

Human dermal fibroblasts (hDF, European Collection of Authenticated Cell Cultures (ECACC)) were cultured in DMEM-F12 medium and THP-1 human monocytes (ECACC) were cultured in RPM1-1640 medium, in a humidified atmosphere $5 \% \mathrm{CO}_{2}$ at $37{ }^{\circ} \mathrm{C}$. Both mediums were supplemented with $10 \%$ (v/ v) FBS (heat inactivated when added to RPMI-1640 medium), $100 \mathrm{IU} \mathrm{mL}^{-1}$ penicillin, $100 \mu \mathrm{g} \mathrm{mL}^{-1}$ streptomycin. hDF cells were harvested using trypsin-EDTA treatment. THP-1 and hDF cells were counted using a hemocytometer and cell viability was assessed through trypan blue staining (95-99\% viable cells).

\section{Indirect toxicity test}

The leakage of potentially toxic products from DAC and sulfonated samples was analyzed by indirect toxicity tests. The experiments were carried out in compliance with the ISO-10993-5 procedure (ISO10993-5 2009). The test materials were extracted for $24 \pm 2 \mathrm{~h}$ in cell culture medium (supplemented DMEM-F12 or supplemented RPMI-1640) at $37{ }^{\circ} \mathrm{C}$ and the extract medium was then used for culturing the cells. The powders were pre-soaked with cell culture medium and thereafter $1 \mathrm{~mL}$ of culture medium per $0.2 \mathrm{~g}$ of material was used for the extraction. The medium extracts were collected and centrifuged at $2000 \mathrm{~g}$ for $10 \mathrm{~min}$, and thereafter sterilized by filtration $(0.2 \mu \mathrm{m}$ filter $)$. hDF cell suspensions in medium extract were prepared at a density of 90,000 cells $\mathrm{mL}^{-1}$ and $100 \mu \mathrm{L}$ were added to the wells of 96 well-tissue culture plates. For the THP-1 cells, the suspensions were prepared in the medium extracts at a density of 300,000 cells $\mathrm{mL}^{-1}$ and $500 \mu \mathrm{L}$ of each suspension were added to 24 well- 
tissue culture plates. The negative control was the medium extract of tissue culture plate (TCP) and the positive control was 5\% dimethylsulfoxide (DMSO) in cell culture medium. Cells were cultured for $24 \pm 2 \mathrm{~h}$ in a $37{ }^{\circ} \mathrm{C}, 5 \% \mathrm{CO}_{2}$ incubator with humidified atmosphere. The samples were run in triplicates and each experiment was repeated at least 3 times.

After incubation, cell viability was determined by the alamar blue assay. For the hDF cells, cell culture medium was removed from the wells and the wells were carefully washed with PBS before adding $100 \mu \mathrm{L}$ of alamar blue reagent diluted 1:10 in PBS. After 90 min incubation in a $37{ }^{\circ} \mathrm{C}$ and $5 \% \mathrm{CO}_{2}$ incubator with humidified atmosphere, $100 \mu \mathrm{L}$ aliquots were transferred to a black 96 well culture plate and the fluorescence intensity was measured by a spectrofluorometer (Tecan Infinite M200, Switzerland) at $560 \mathrm{~nm}$ excitation wavelength and $590 \mathrm{~nm}$ emission wavelength.

THP-1 cell suspensions were collected in Eppendorf tubes and centrifuged at $500 \mathrm{~g}$ for $5 \mathrm{~min}$, cells were then re-suspended in $500 \mu \mathrm{L}$ of fresh cell culture medium and transferred to another 24 well-tissue plate. Alamar blue solution, $50 \mu \mathrm{L}$, was added to the wells and incubated and analyzed as described for the $\mathrm{hDF}$ cells. Results are presented as percentage of cell viability of the negative control.

\section{Light microscopy}

Adherent hDF cells were observed under light microscopy (Nikon Eclipse TE2000-U) to evaluate their morphology. The extract medium was removed from the wells after $24 \mathrm{~h}$ culture, and the wells were carefully rinsed with PBS prior the microscopy observation.

\section{Statistical analysis}

The software R was used to perform statistical analysis with one way ANOVA (LSD and Tamhane post hoc test). $p$ values $<0.05$ were considered to be statistically significant.

\section{Results and discussion}

Cladophora nanocellulose was chemically modified into 2,3-dialdehyde cellulose and its sulfonated derivatives as schematically shown in Fig. 1. The periodate oxidation led to DAC beads following a procedure developed by Lindh et al. (2014) using a one-pot procedure in aqueous medium. The produced DAC beads had $95 \%$ conversion of the 2,3-hydroxyl groups to aldehydes according to elemental analysis data.

Following the oxidation, a sulfonation reaction was performed using the method developed by Zhang et al. (2007) and about 50\% degree of sulfonation was intended. This degree of sulfonation was chosen in order to preserve the other half of the aldehyde groups for future coupling with specific antibodies. An additional step was performed to reduce the remaining aldehyde groups back to hydroxyl groups, obtaining the RSDAC sample used in the cell toxicity studies.

The periodate oxidation reaction leads to full conversion of the vicinal $\mathrm{OH}$ groups into aldehydes in $240 \mathrm{~h}$ and the course of the reaction could be followed by FTIR spectroscopy and microscopy. Figure 2 shows the spectra corresponding to the formation of the dialdehyde groups with the increase of the bands centered at 1730 and $880 \mathrm{~cm}^{-1}$, corresponding to the carbonyl and hemiacetal groups respectively (Kim et al. 2000).

The formation of DAC beads was also followed by light microscopy and SEM. Figure 3a displays light microscopy images showing the changes in the morphology of the cellulose from an undefined morphology to round shaped structures dispersed in a solvent droplet, while Fig. 3b shows the surface of the material in more detail as observed by SEM.

The DAC beads were sulfonated with the aim of introducing heparin-like moieties that could render the material with anticoagulant properties. The physicochemical properties of the sulfonated material were investigated and compared with its precursor (Table 1). The elemental analysis and the conductometric titration confirmed the successful introduction of the sulfate groups (Table 1), while the beads morphology was maintained (Fig. 4).

Light diffraction analysis was performed to determine the particle size distribution and showed that the size of the wet DAC beads was in the range of $5-22 \mu \mathrm{m}$ as shown in Table 1. The degree of sulfonation achieved was $48 \%$, as determined via conductometric titration.

The BET analysis shows that the SDAC beads have higher surface area $\left(106 \mathrm{~m}^{2} \mathrm{~g}^{-1}\right)$ compared to the 


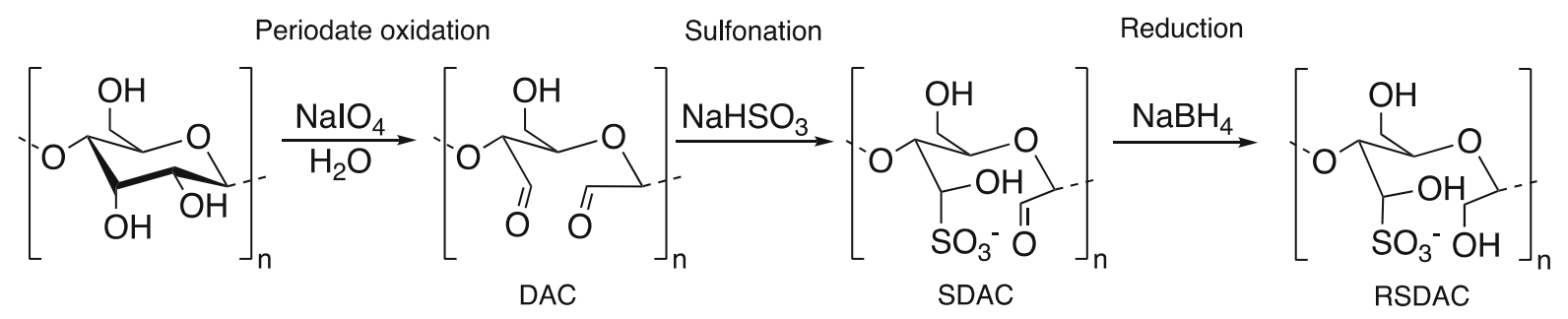

Fig. 1 Schematic representation of the chemical modifications of the Cladophora nanocellulose

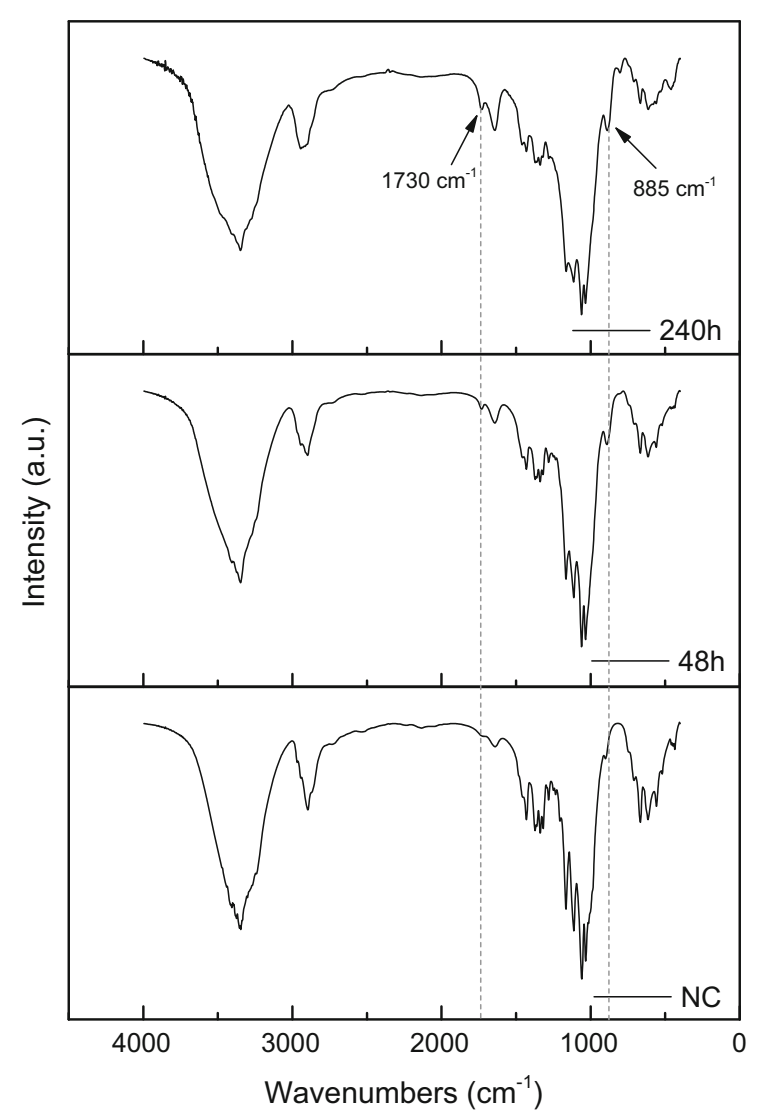

Fig. 2 Periodate oxidation reaction followed by FTIR spectroscopy. Observe the intensity increase with time of the bands centered at 1730 and $885 \mathrm{~cm}^{-1}$ that correspond to the carbonyl and hemiacetal groups respectively

DAC beads $\left(19 \mathrm{~m}^{2} \mathrm{~g}^{-1}\right)$, and to the unmodified material $\left(96 \mathrm{~m}^{2} \mathrm{~g}^{-1}\right)$, and also when compared to other immunosorbent materials based on polymeric beads as reported by Saylan et al. of 17.4 and $18.7 \mathrm{~m}^{2} \mathrm{~g}^{-1}$ for poly(2-hydroxyethyl methacrylate) and for poly(2-hydroxyethyl methacrylate-Nmethacryloyl-L-phenylalanine) respectively (Saylan et al. 2012).
Figure 4 shows SEM images of unmodified nanocellulose, DAC and SDAC depicting the change in morphology from packed fibers to beads with smooth surfaces to beads with highly porous structure, respectively. The change in porous structure when sulfonate groups are introduced could be explained by the increase of charge due to sulfonation that causes repulsion of the fibers and thus increases the porosity, while the interactions between the aldehyde groups make the fibers interact stronger with each other via hydrogen bonds within hydroxyl groups in neighboring chains.

Figure 5 shows the pore size distribution of the different materials measured by nitrogen sorption analysis. The values corresponding to the SDAC and RSDAC samples, between 20 and $60 \mathrm{~nm}$, are larger than the pore width of the unmodified Cladophora nanocellulose, between 8 and $20 \mathrm{~nm}$, and much larger than the DAC beads which have most of the pores between 1 and $8 \mathrm{~nm}$, corroborating the SEM images shown above. The mesoporous range of the sulfonated DAC beads opens up the possibility of using the beads in protein retention systems (Wang et al. 2007; Ettenauer et al. 2011). Cellulose membranes initially used as immunosorbents possessed mostly small pores which allowed the passage of excess fluid but blocked the removal of bigger proteins, causing their accumulation in the blood and leading to health problems (Davankov et al. 2000).

Cellulose-based immunosorption devices are used in in vitro and clinical research and are also available as commercial products, e.g. Lixelle ${ }^{\mathrm{TM}}$ (Kaneka Corporation, Osaka, Japan). These materials are, however, expensive due to their way of production, and they are all based on non nanocellulosic materials (Kutsuki 2005; Yu 2013). Sulfonated cellulose materials have been studied as adsorbents for water treatment, (Dong et al. 2016) and Selesorb $\subset$ (Kaneka Corporation, Osaka, Japan) is a clinically used 

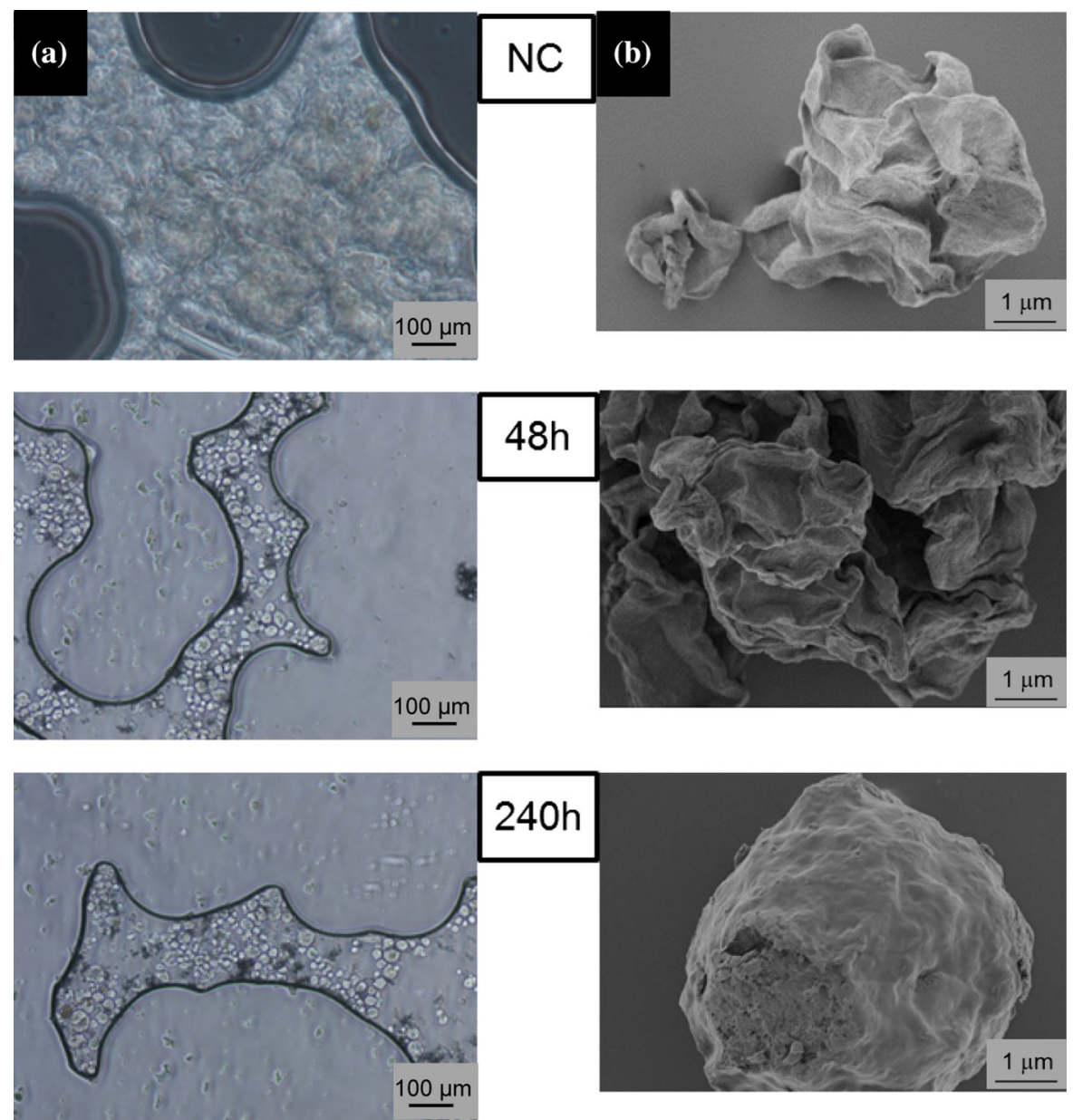

Fig. 3 Periodate oxidation reaction followed by: a light microscopy, b SEM

Table 1 Physicochemical properties of the different Cladophora nanocellulose materials

\begin{tabular}{lllll}
\hline & Unmodified & DAC & SDAC & RSDAC \\
\hline$\% \mathrm{~S}(\mathrm{CHNS})$ & 0 & 0 & 13.50 & 13.60 \\
BET surface area $\left(\mathrm{m}^{2} \mathrm{~g}^{-1}\right)$ & 96 & 19 & 106 & 90 \\
Total pore volume $\left(\mathrm{cm}^{3} \mathrm{~g}^{-1}\right)$ & 0.44 & 0.10 & 0.27 & 0.20 \\
Amount of charged $\mathrm{groups}\left(\mu \mathrm{mol} \mathrm{g} \mathrm{g}^{-1}\right)$ & $32 \pm 2$ & $30 \pm 5$ & $495 \pm 3$ & $486 \pm 5$ \\
$\zeta$-Potential at $\mathrm{pH} 6.5(\mathrm{mV})$ & $-8 \pm 3$ & $-12 \pm 2$ & $-29 \pm 5$ & $-25 \pm 3$ \\
Particle size d50 $(\mu \mathrm{m})$ & & $13 \pm 8$ & $15 \pm 6$ & $17 \pm 5$ \\
\hline
\end{tabular}

immunosorbent based on cellulose modified with dextrane sulfate. Further, nanocellulose has been recently used for wastewater purification (Putro et al. 2017). However, to the best of our knowledge there is no report of a sulfonated nanocellulosic material for immunosorption. As an initial step towards developing a nanocellulose based sulfonated material intended for immunosorption applications, thorough material characterization and cytotoxicity studies were deemed important.

Before the cytotoxicity tests, an extra step was taken to reduce the remaining aldehyde groups in the SDAC sample back to hydroxyl groups, obtaining the RSDAC material (Fig. 1). This was done because the aldehyde groups are known to interact with proteins and this could influence the material-cell interactions 

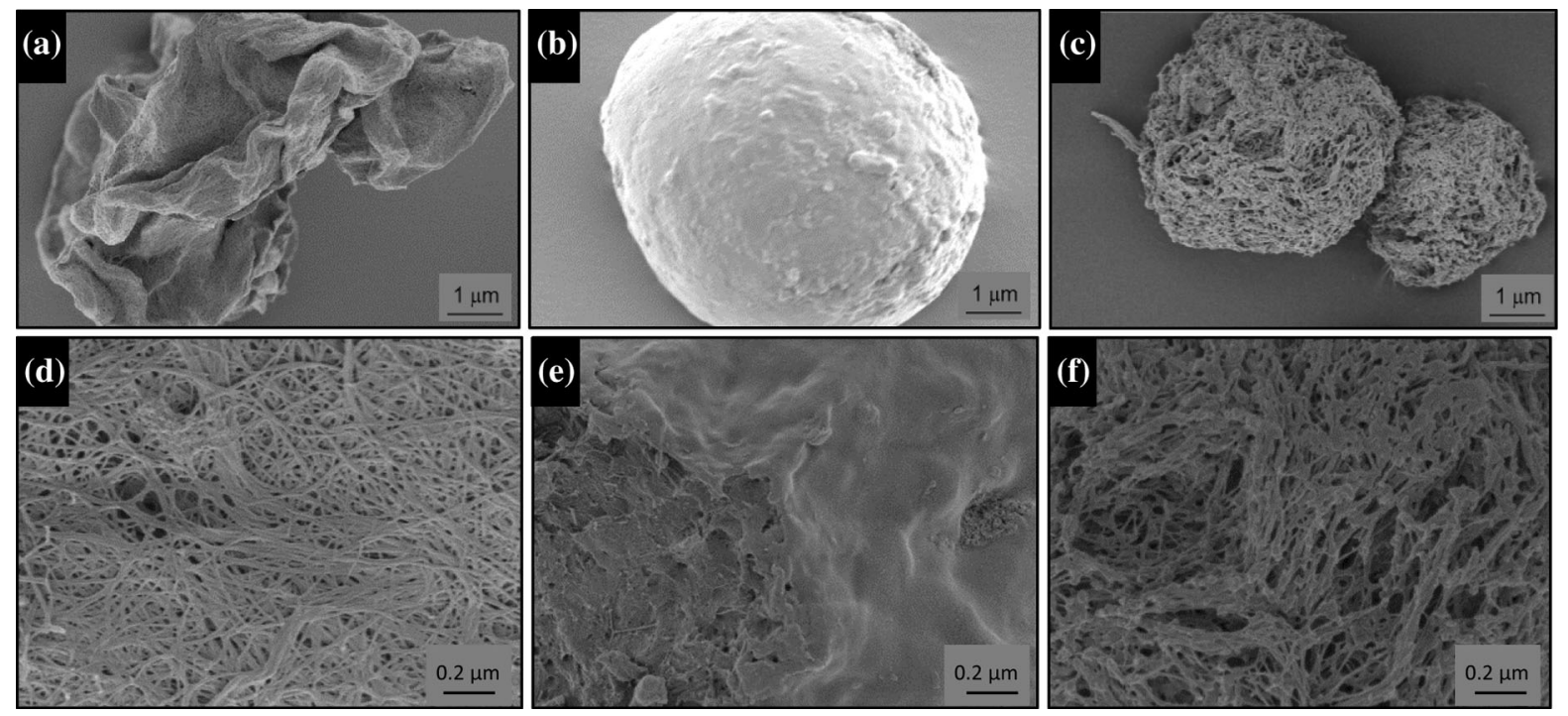

Fig. 4 SEM images of: a unmodified Cladophora nanocellulose, b DAC and $\mathbf{c}$ SDAC showing the changes in morphology with the chemical modifications. Images $\mathbf{d}-\mathbf{f}$ show higher magnification images of the same materials where the pore structures can be observed

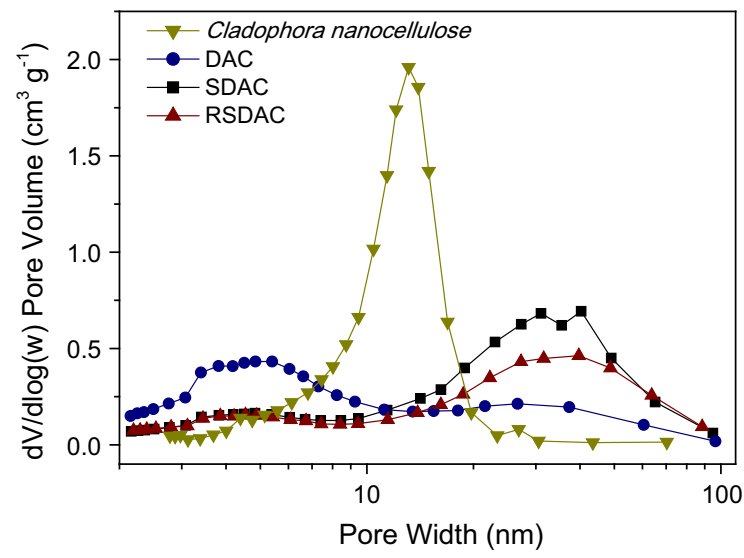

Fig. 5 Pore size distribution of the different cellulosic materials

in future bioapplications of the sulfonated beads (Beauchamp et al. 1992). The reduction step preserved the beads morphology (Fig. 6) and size, however a decrease in specific surface area and in total pore volume was observed (Table 1). SEM images in Fig. 6 also reflect the decrease in the porosity of the RSDAC material compared with SDAC.

hDF cells and THP-1 monocytes were selected as model cells for the indirect toxicity studies. Fibroblasts are usually recommended as model cells for indirect tests, (ISO10993-5 2009) while monocytes are relevant for the proposed application of the sulfonated nanocellulose material, where the material will be in contact with blood. Figure 7 a shows the results of the indirect tests with $\mathrm{hDF}$ cells for the different materials. DAC and SDAC samples showed very low levels of cell viability, while cell number markedly increased when the cells were cultured with RSDAC extract.

The light microscopy images of adherent hDF presented in Fig. 8 correlate with the cell viability results displayed in Fig. 7a. Images show that only cells cultured in RSDAC extracts adhere in great number and present spread-like morphology, comparable to the cell morphology observed in the negative control. Cells cultured in extracts of DAC and SDAC samples showed round-shape morphology, resembling the cell images observed with the positive control.

At first, when looking at the morphology of the cells cultured in SDAC extract it could be hypothesized that a change in the ionic strength of the extract medium may be the reason behind the poor cell viability. However, no visible differences in color change between the phenol red-containing medium extracts of SDAC and RSDAC were observed.

In the case of the THP-1 monocytes, it was found that the non-toxic characteristic of the RSDAC sample previously described with the hDF cells could not be confirmed with the monocyte cell line (Fig. 7b). An increase in cell viability was observed with the RSDAC extract compared with the non-reduced 

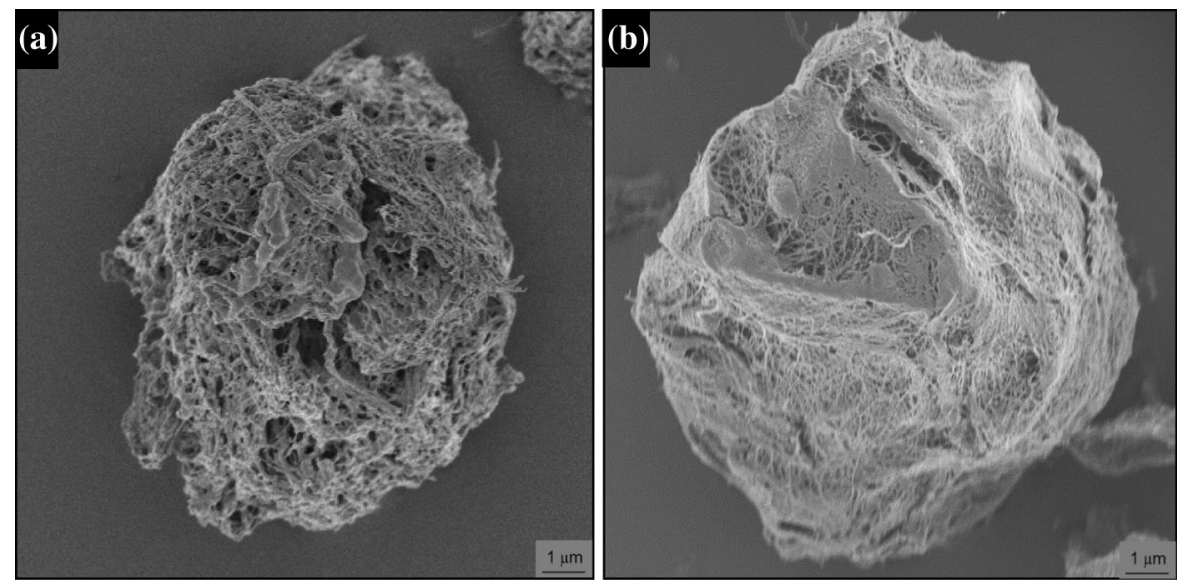

Fig. 6 SEM images of the sulfonated beads: a SDAC (non-reduced), b RSDAC (reduced)

(a)

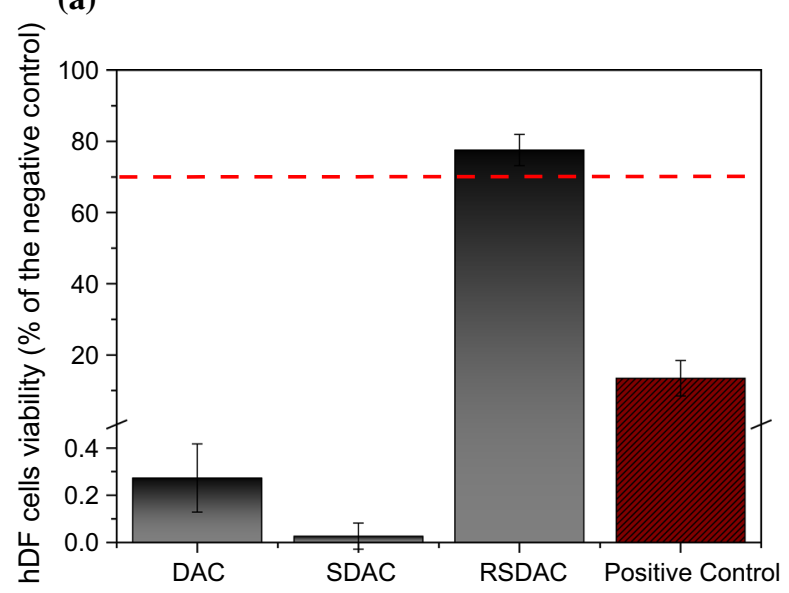

Fig. 7 Cell viability cells cultured for $24 \mathrm{~h}$ in extracts of the Cladophora nanocellulose modified samples. The negative control was the extract medium of tissue culture plate while the positive control was $5 \%$ DMSO in cell culture medium. Data

sample SDAC but the values were below the toxicity limit and statistically significantly different from the negative control. The high surface area and pore volume of the beads might be responsible for the retention and lower availability of cell culture medium proteins, amino acids and growth factors needed for the proliferation of the non-adherent THP-1 cells, while the anchorage-dependent fibroblasts are less sensitive to such changes in the cell culture medium composition.

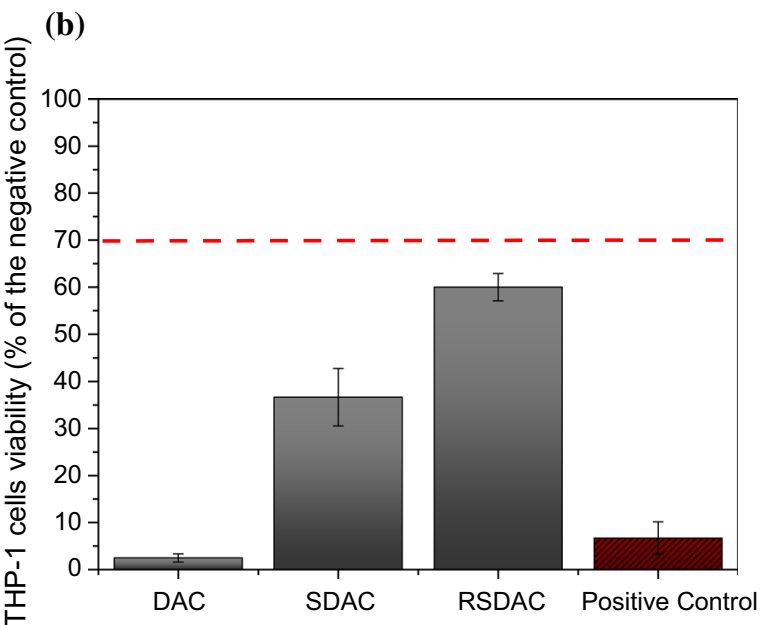

represent the mean \pm SE of the mean. Cell viability values above $70 \%$ indicate non-cytotoxic effects: a hDF cells, b THP-1 cells

\section{Conclusions}

A novel method to produce sulfonated micrometersized porous beads from Cladophora nanocellulose via facile and mild reactions was developed. The beadforming step of the method relies on periodate oxidation, which leads to a convenient spontaneous formation of spherical DAC particles in a one-pot procedure. The spherical beads obtained had an average diameter of $15 \mu \mathrm{m}$ and a high surface area in the range of $100 \mathrm{~m}^{2} \mathrm{~g}^{-1}$ and pore sizes between 20 and $60 \mathrm{~nm}$, making them interesting candidates for sorption materials. The cytotoxicity studies showed 


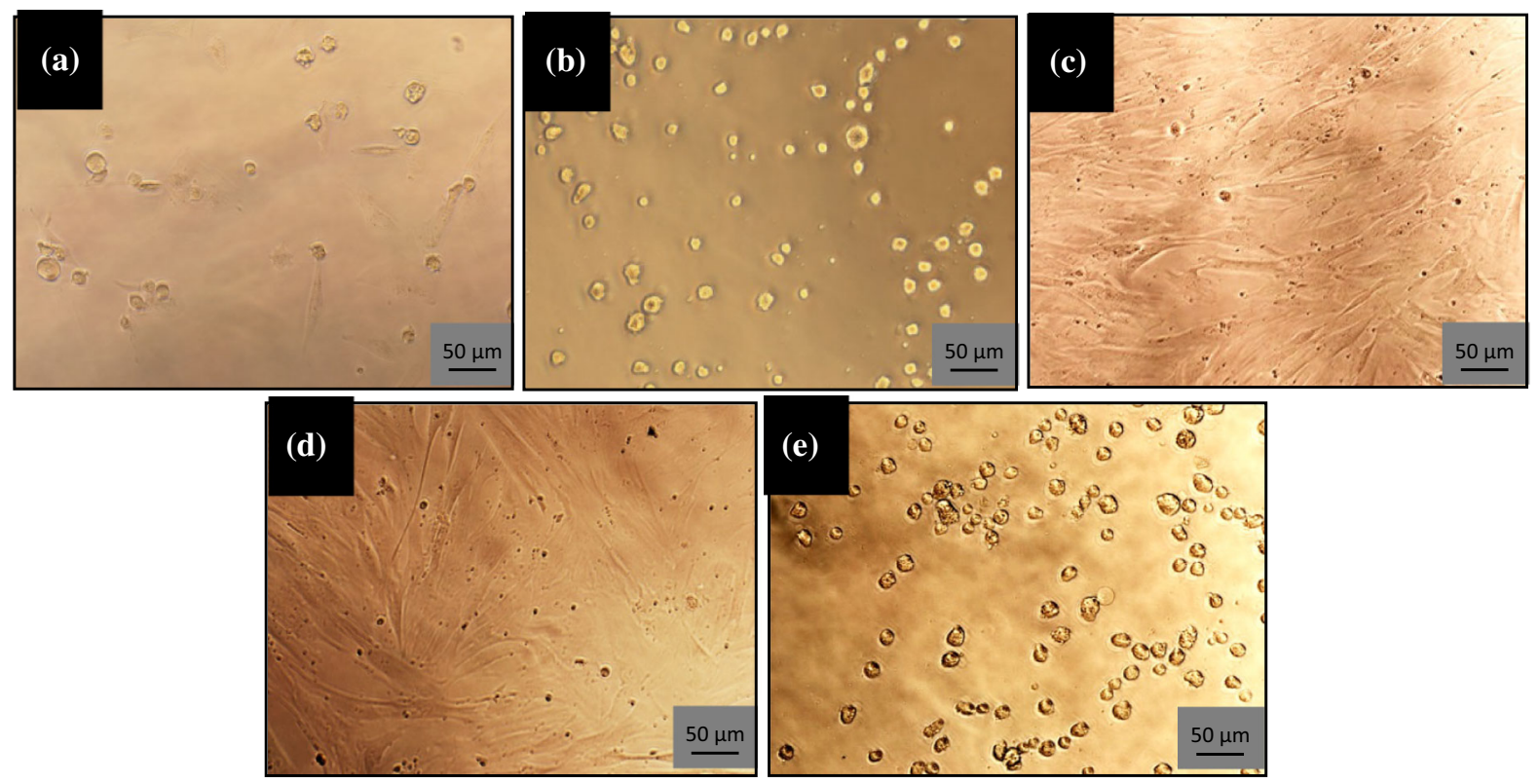

Fig. 8 Representative light microscopy images of the hDF cells after 24 h culture in extracts of: a DAC b SDAC, $\mathbf{c}$ RSDAC, d TCP (negative control), e 5\% DMSO in cell culture medium (positive control)

the need of reducing the remaining aldehyde groups in order to modulate the indirect cytotoxicity of the material. Studies regarding hemocompatibility should be carried out to further investigate the potential of the sulfonated beads in the development of non-thrombogenic immunosorbent platforms.

Acknowledgments I. R. thanks the Brazilian Ministry of Education and the CAPES agency for financial support. J. L. and A. M. thank Knut and Alice Wallenberg Foundation for financial support within Wallenberg Academy Fellowship program.

Open Access This article is distributed under the terms of the Creative Commons Attribution 4.0 International License (http:// creativecommons.org/licenses/by/4.0/), which permits unrestricted use, distribution, and reproduction in any medium, provided you give appropriate credit to the original author(s) and the source, provide a link to the Creative Commons license, and indicate if changes were made.

\section{References}

Alban S (2005) From heparins to factor Xa inhibitors and beyond. Eur J Clin Invest 35:12-20. https://doi.org/10. 1111/j.0960-135X.2005.01452.x

Asper M, Hanrieder T, Quellmalz A, Mihranyan A (2015) Removal of xenotropic murine leukemia virus by nanocellulose based filter paper. Biologicals 43:452-456. https://doi.org/10.1016/j.biologicals.2015.08.001

Beauchamp RO, Clair MBGS, Fennell TR, Clarke DO, Morgan KT (1992) A critical review of the toxicology of glutaraldehyde. Crit Rev Toxicol 22:143-174. https://doi.org/ 10.3109/10408449209145322

Beck S, Méthot M, Bouchard J, Me M, Bouchard J (2015) General procedure for determining cellulose nanocrystal sulfate half-ester content by conductometric titration. Cellulose 22:101-116. https://doi.org/10.1007/s10570014-0513-y

Brunauer S, Emmett PH, Teller E (1938) Adsorption of gases in multimolecular layers. J Am Chem Soc 60:309-319

Cosmi B, Palareti G (2012) Old and new heparins. Thromb Res 129:388-391. https://doi.org/10.1016/j.thromres.2011.11. 008

Davankov V, Pavlova L, Tsyurupa M, Brady J, Balsamo M, Yousha E (2000) Polymeric adsorbent for removing toxic proteins from blood of patients with kidney failure. J Chromatogr B Biomed Sci Appl 739:73-80. https://doi. org/10.1016/S0378-4347(99)00554-X

Dong C, Zhang F, Pang Z, Yang G (2016) Efficient and selective adsorption of multi-metal ions using sulfonated cellulose as adsorbent. Carbohydr Polym 151:230-236. https://doi. org/10.1016/j.carbpol.2016.05.066

Dufresne A (2013) Nanocellulose: a new ageless bionanomaterial. Mater Today 16:220-227. https://doi.org/10.1016/j. mattod.2013.06.004

Ettenauer M, Loth F, Thümmler K, Fischer S, Weber V, Falkenhagen D (2011) Characterization and functionalization of cellulose microbeads for extracorporeal blood purification. Cellulose 18:1257-1263. https://doi.org/10. 1007/s10570-011-9567-2 
Ferraz N, Mihranyan A (2014) Is there a future for electrochemically assisted hemodialysis? Focus on the application of polypyrrole-nanocellulose composites. Nanomedicine 9: 1095-1110. https://doi.org/10.2217/nnm.14.49

Ferraz N, Carlsson DO, Hong J, Larsson R, Fellström B, Nyholm L, Strømme M, Mihranyan A (2012) Haemocompatibility and ion exchange capability of nanocellulose polypyrrole membranes intended for blood purification. J R Soc Interface 9:1943-1955. https://doi.org/10.1098/rsif. 2012.0019

Ferraz N, Leschinskaya A, Toomadj F, Fellström B, Strømme M, Mihranyan A (2013) Membrane characterization and solute diffusion in porous composite nanocellulose membranes for hemodialysis. Cellulose 20:2959-2970. https:// doi.org/10.1007/s10570-013-0045-x

Gericke M, Trygg J, Fardim P (2013) Functional cellulose beads: preparation, characterization, and applications. Chem Rev 113:4812-4836. https://doi.org/10.1021/cr300242j

Gorbet MB, Sefton MV (2004) Biomaterial-associated thrombosis: roles of coagulation factors, complement, platelets and leukocytes. Biomaterials 25:5681-5703. https://doi. org/10.1016/j.biomaterials.2004.01.023

Gustafsson S, Lordat P, Hanrieder T, Asper M, Schaefer O, Mihranyan A (2016) Mille-feuille paper: a novel type of filter architecture for advanced virus separation applications. Mater Horizons 3:320-327. https://doi.org/10.1039/ C6MH00090H

ISO10993-5 (2009) ISO10993-5

Junqueira DRG, Carvalho MDG, Perini E (2013) Heparin-induced thrombocytopenia: a review of concepts regarding a dangerous adverse drug reaction. Rev Assoc Med Bras 59: 161-166. https://doi.org/10.1016/S2255-4823(13)70450-8

Kim UJ, Kuga S, Wada M, Okano T, Kondo T (2000) Periodate oxidation of crystalline cellulose. Biomacromol 1:488-492

Kutsuki H (2005) $\beta 2$-Microglobulin-selective direct hemoperfusion column for the treatment of dialysis-related amyloidosis. Biochim Biophys Acta Prot Proteom 1753:141145. https://doi.org/10.1016/j.bbapap.2005.08.007

Landers J, Gor GY, Neimark AV (2013) Colloids and surfaces A: physicochemical and engineering aspects density functional theory methods for characterization of porous materials. Colloids Surf A Physicochem Eng Asp 437:3-32. https://doi.org/10.1016/j.colsurfa.2013.01.007

Lindh J, Carlsson DO, Strømme M, Mihranyan A (2014) Convenient one-pot formation of 2,3-dialdehyde cellulose beads via periodate oxidation of cellulose in water. Biomacromol 15:1928-1932. https://doi.org/10.1021/bm5002944

Lindh J, Ruan C, Strømme M, Mihranyan A (2016) Preparation of porous cellulose beads via introduction of diamine spacers. Langmuir 32:5600-5607

Lloyd JA, Horne CW, Zealand N (1993) The determination of fibre charge and acidic groups of radiata pine pulps. Nord Pulp Pap Res J 111993:3-8

Maas NC, Gracher AHP, Sassaki GL, Gorin PAJ, Iacomini M, Cipriani TR (2012) Sulfation pattern of citrus pectin and its carboxy-reduced derivatives: influence on anticoagulant and antithrombotic effects. Carbohydr Polym 89:1081-1087. https://doi.org/10.1016/j.carbpol.2012.03.070

Metreveli G, Wågberg L, Emmoth E, Belák S, Strømme M, Mihranyan A (2014) A size-exclusion nanocellulose filter paper for virus removal. Adv Healthc Mater 3:1546-1550. https://doi.org/10.1002/adhm.201300641

Mihranyan A (2010) Cellulose from cladophorales green algae: from environmental problem to high-tech composite materials. J Appl Polym Sci 119:2449-2460. https://doi. org/10.1002/app

Mihranyan A, Edsman K, Strømme M (2007) Rheological properties of cellulose hydrogels prepared from Cladophora cellulose powder. Food Hydrocoll 21:267-272. https://doi.org/10.1016/j.foodhyd.2006.04.003

Olson ST, Björk I (1993) Mechanism of action of heparin and heparin-like antithrombotics. Perspect Drug Discov Des $1: 479-501$

Putro JN, Kurniawan A, Ismadji S, Ju Y (2017) Nanocellulose based biosorbents for wastewater treatment: study of isotherm, kinetic, thermodynamic and reusability. Environ Nanotechnol Monit Manag 8:134-149. https://doi.org/10. 1016/j.enmm.2017.07.002

Ran F, Nie S, Li J, Su B, Sun S, Zhao C (2012) Heparin-like macromolecules for the modification of anticoagulant biomaterials. Macromol Biosci 12:116-125. https://doi. org/10.1002/mabi.201100249

Razaq A, Nyström G, Strømme M, Mihranyan A, Nyholm L (2011) High-capacity conductive nanocellulose paper sheets for electrochemically controlled extraction of DNA oligomers. PLoS ONE 6:1-9. https://doi.org/10.1371/ journal.pone.0029243

Ruan C, Strømme M, Lindh J (2016) A green and simple method for preparation of an efficient palladium adsorbent based on cysteine functionalized 2,3-dialdehyde cellulose. Cellulose 23:2627-2638. https://doi.org/10.1007/s10570-0160976-0

Salmivirta M, Lindholt K, Lindahl U (1996) Heparan sulfate: a piece of information. FASEB J 10:1270-1279

Saylan Y, Sari MM, Özkara S, Uzun L, Denizli A (2012) Hydrophobic microbeads as an alternative pseudo-affinity adsorbent for recombinant human interferon- $\alpha$ via hydropho-

bic interactions. Mater Sci Eng C 32:937-944. https://doi. org/10.1016/j.msec.2012.02.016

Silver JH, Hart AP, Williams EC, Cooper SL, Charef S, Labarre D, Jozefowicz M (1992) Anticoagulant effects of sulphonated polyurethanes. Biomaterials 13:339-344. https://doi. org/10.1016/0142-9612(92)90037-O

Tamada Y, Murata M, Makino K, Yoshida Y, Yoshida T, Hayashi T (1998) Anticoagulant effects of sulphonated polpisoprenes. Biomaterials 19:745-750. https://doi.org/ 10.1016/S0142-9612(97)00207-X

Tamada Y, Murata M, Hayashi T, Goto K (2002) Anticoagulant mechanism of sulfonated polyisoprenes. Biomaterials 23: 1375-1382. https://doi.org/10.1016/S0142-9612(01)00258-7

Wang D-M, Hao G, Shi Q-H, Sun Y (2007) Fabrication and characterization of superporous cellulose bead for highspeed protein chromatography. J Chromatogr A 1146: 32-40. https://doi.org/10.1016/j.chroma.2007.01.089

Weber V, Linsberger I, Ettenauer M, Loth F, Höyhtyä M, Falkenhagen D (2005) Development of specific adsorbents for human tumor necrosis factor-alpha: influence of antibody immobilization on performance and biocompatibility. Biomacromol 6:1864-1870. https://doi.org/10.1021/ bm040074t 
Weber V, Ettenauer M, Linsberger I, Loth F, Thümmler K, Feldner A, Fischer S, Falkenhagen D (2010) Functionalization and application of cellulose microparticles as adsorbents in extracorporeal blood purification. Macromol Symp 294: 90-95. https://doi.org/10.1002/masy.200900042

Xu C, Carlsson DO, Mihranyan A (2016) Feasibility of using DNA-immobilized nanocellulose-based immunoadsorbent for systemic lupus erythematosus plasmapheresis. Colloids
Surf B Biointerfaces 143:1-6. https://doi.org/10.1016/j. colsurfb.2016.03.014

Yu YT (2013) Adsorbents in blood purification: From lab search to clinical therapy. Chin Sci Bull 58:4357-4361. https:// doi.org/10.1007/s11434-013-6071-0

Zhang J, Jiang N, Dang Z, Elder TJ, Ragauskas AJ (2007) Oxidation and sulfonation of cellulosics. Cellulose 15:489-496. https://doi.org/10.1007/s10570-007-9193-1 